\title{
Bio-Swale Column Experiments and Simulation of Hydrologic Impacts on Urban Road Stormwater Runoff
}

\author{
Jiake Li ${ }^{1 *}$, Ya Li ${ }^{1}$, Jiayang Zhang', Huaien $\mathrm{Li}^{1}$, Yajiao $\mathbf{L i}^{3}$ \\ ${ }^{1}$ State Key Laboratory Base of Eco-Hydraulic Engineering in Arid area, \\ Xi'an University of Technology, Xi'an, Shaanxi 710048, China \\ ${ }^{2}$ School of Architecture and Civil Engineering, Xi'an University of Science and Technology, \\ Xi'an, Shaanxi 710054, China
}

Received: 4 September 2015

Accepted: 19 October 2015

\begin{abstract}
The acceleration of urbanization has resulted in the increase of urban surface runoff. Bio-swale is a promising stormwater control measure that has been proven to be hydrologically effective on urban surface runoff. Column studies were conducted to determine the optimal bio-swale composition. Results demonstrated that water reduction was proportional to inflow decrease. Columns that planted border privet and Ophiopogon japonicus showed a larger water quantity reduction compared with that of planted boxwood and ryegrass, glossy privet and Chlorophytum comosum 'Variegatum' in vegetation tests, which was the same as the order of measured transpiration capacity of the plants. Water reduction rate increases dramatically with decreasing planting soil thickness. By contrast, no significant change occurs once the thickness of the artificial filler layer is altered. The bio-swale column with a high-infiltration rate artificial filler produced a good hydrological control effect. Sand was found to be the optimal media among the selected media compositions. Although the inclusion of an additional ponding depth affected total water reduction, it produced a stable outflow. SPSS software was used to assess the relationship between water reduction rate and its influence. On the one hand, water reduction rate increased linearly with increasing water inflow, soil thickness, and ponding depth. On the other, water reduction rate grew linearly with increasing plant factor and artificial filler infiltration rate. The multiple linear regression model revealing the relationship between the water reduction effect, and its influencing factors were obtained via the stepwise regression method in the SPSS software.
\end{abstract}

Keywords: bio-swale urban road runoff, water reduction, SPSS, multiple stepwise regression model

\section{Introduction}

The urban impermeable area ratio grows with rapid urbanization. The construction of rooftops, paved road-

*e-mail: xaut_ljk@163.com ways, and parking lots greatly modifies the hydrological characteristics of rainfall runoff from the corresponding land area. Consequently, urban surface runoff has worsened, and hydrological balance is compromised. Today, urban stormwater runoff is widely recognized as a primary driver of environmental degradation in urban watersheds [1]. 
Low impact development (LID) is an alternative stormwater management approach that could effectively sustain the natural flow regime [2-4]. The goal of this approach is to manage site design and construction so that the hydrology and water quality of a developed site is approximately the same as that of the initial undeveloped land. The LID approach minimizes grading, disconnects impervious areas, preserves the existing landscape and topography, increases flow lengths, and lengthens the concentration time for stormwater runoff [5].

Bioretention/bio-swale has been proven to be a stormwater control measure of LID that can successfully manage flows and volume [6-8]. To date, bioretention facilities have demonstrated good hydrological performance. Hunt et al. [9] found that all outflow volumes were less than $50 \%$ of the inflow volumes at three bioretention field sites in North Carolina (USA) over the course of one year. Heasom et al. [10] noted the absence of surface water discharge below a particular baseline event. In another study, Hunt et al. [11] showed that a peak reduction of $96 \%$ was observed in storm events producing less than $4 \mathrm{~cm}$ of rainfall. Davis et al. [12] noted that $18 \%$ of 49 rainfall events were entirely captured by bioretention facilities . In addition, flow peaks were reduced by $44-63 \%$ and were delayed significantly, usually by a factor of two or more. Li et al. [13] investigated hydrological performance at six bioretention cells in Maryland (USA) and found that bioretention can mitigate the post development hydrology caused by impervious surfaces. In addition, they demonstrated that bioretention exhibits excellent hydrological performance for small rain events, but its performance deteriorates under more extreme precipitation events. Davis et al. [14] defined the bioretention abstraction volume (BAV) as the storage volume for a bioretention cell that will fill before underdrain or overflow discharge occurs.

The BAV was validated by field data from mid-Atlantic bioretention sites. In addition, the volume of removal can be predicted. Thus, it can serve as a quantitative design tool for bioretention in urban stormwater management.

A research overview and summation by Hunt et al. [15] established design guidelines that target specific hydrological and water-quality goals by adjusting bioretention design parameters such as bowl volume, media composition, media depth, underdrainage configuration, and vegetation type. Olszewski and Davis [16] noted that the bioretention facility in the Silver Spring outflow depends on media saturation and ponding depth, in contrast to the cell inflow, which directly responds to rainfall and rainfall intensity. This indirect relationship with rainfall makes outflow rates significantly smaller and more constant than inflow rates.

Additionally, a lot of column experiments about bioretention have been carried out. Barrett et al. [17] conducted a nine-month column study using synthetic stormwater to compare the pollutant removal effectiveness of biofiltration systems containing different media and plant species. O'Neill and Davis [18] utilized two large gravitydriven vegetated columns to investigate the water treatment residual as a bioretention amendment for phosphorus. Batch and minicolumn studies were employed to study the use of aluminum-based water treatment residual (WTR) as a bioretention soil media (BSM) amendment. Moreover, a $5 \%$ water treatment residual and 3\% triple-shredded hardwood bark mulchamended loamy sand BSM was investigated in a largescale column to determine the media $P$ adsorption performance under varying hydrological and pollutant concentration conditions [19]. Twenty biofilter columns were monitored over a 12 -month period of dosing with semisynthetic stormwater to investigate the role of filter media, vegetation, and a saturated zone (SZ) in achieving co-optimized nitrogen and phosphorus removal in biofilters [20]. Paus et al. [21] investigated the effects of compost volume fraction on bioretention media hydraulic conductivity, toxic metal capture, and phosphorus (P) release based on the batch and column experiments. Besides, another column experiment research by Paus et al. [22] suggested that bioretention is likely to be effective for metals capture and retention under cold climate conditions, especially when that media contains at least $30 \%$ compost by volume.

A large-scale stormwater biofilter column study was conducted by Feng et al. [23] to evaluate the impact of design configurations and operating conditions, such as vegetation selection, filter media type, filter media depth, inflow volume, and inflow pollutant concentrations, on metal removal for stormwater harvesting and protection of aquatic ecosystems. In another study, Lim et al. [24] recommended using potting soil as the principal media mixed with compost or sludge by comparing the heavy metal removal potential $(\mathrm{Cu}, \mathrm{Zn}, \mathrm{Cd}$, $\mathrm{Pb}$ ) of five materialsbased (potting soil, compost, coconut coir, sludge, and a commercial mix) laboratory column experiments. Small column tests by Guo et al. [25] were conducted on various soil mixes as a rapid evaluation tool for the optimum engineered soil mix, considering its ability to support healthy plant/tree growth, cost-effectiveness, availability in local markets, hydraulic conductivity, and its ease of preparation by local landscape contractors.

Intensive column research has assisted in determining the impacts of design configurations and operating conditions on pollutant removal, and resulting in a lack of understanding as to the relationship between hydrological performance and its influencing factors of bio-swales. This paper aims to identify the main factors that affect bio-swale hydrological performance and to maximize their relationship. Six groups of bio-swale columns with different longitudinal structures were designed and constructed in an outdoor experiment field in Xi'an University of Technology. Under different conditions of inflow, vegetation type, media thickness, artificial media composition, and ponding depth, the hydrological performances of bio-swale columns on urban surface runoff were analyzed based on the measured experiment data. In addition, SPSS software was used to analyze the statistical relationship between water quantity reductions and those factors. 


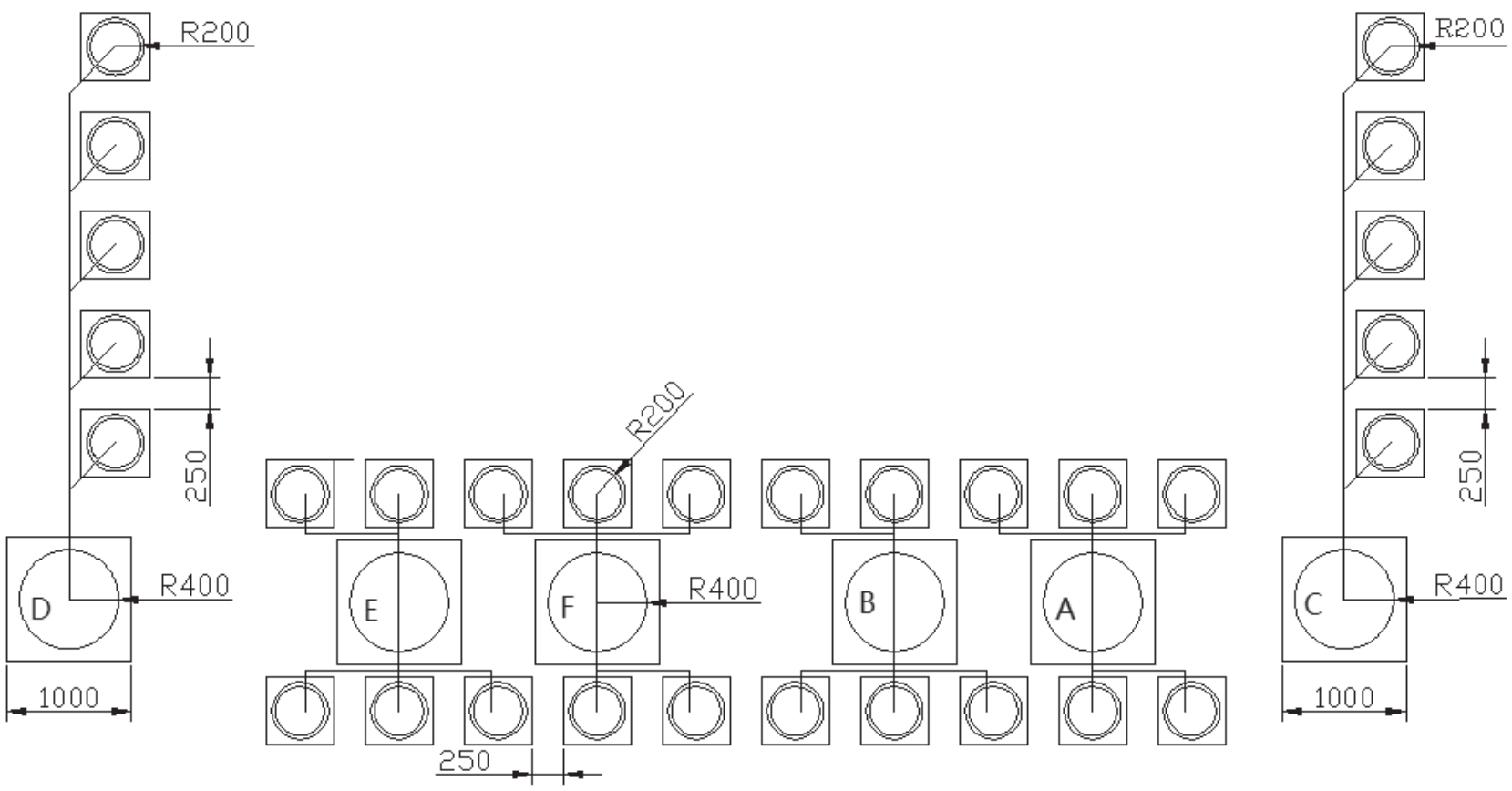

Fig. 1. Plane arrangement of the experiment field (unit: $\mathrm{mm}$ ).

\section{Materials and Methods}

\section{Experimental System}

Thirty bio-swale columns were constructed and divided into six groups. Each bio-swale column was constructed with PVC pipes with inner diameter of 400 $\mathrm{mm}$ and cylinder thickness of $6 \mathrm{~mm}$. The aquifer layer was set to $150 \mathrm{~mm}$. The medium was filled with $50 \mathrm{~mm}$ of mulch, $300 \mathrm{~mm}$ of planting soil, $400 \mathrm{~mm}$ of artificial filler, and $150 \mathrm{~mm}$ of gravel from top to bottom. Sand, planting soil, slag, a 5:1 mixture of sand and coal ash, and 1:1 mixture of sand and slag were sequentially selected as artificial filler from No. 1 to No. 5 in groups A, B, E,

a)

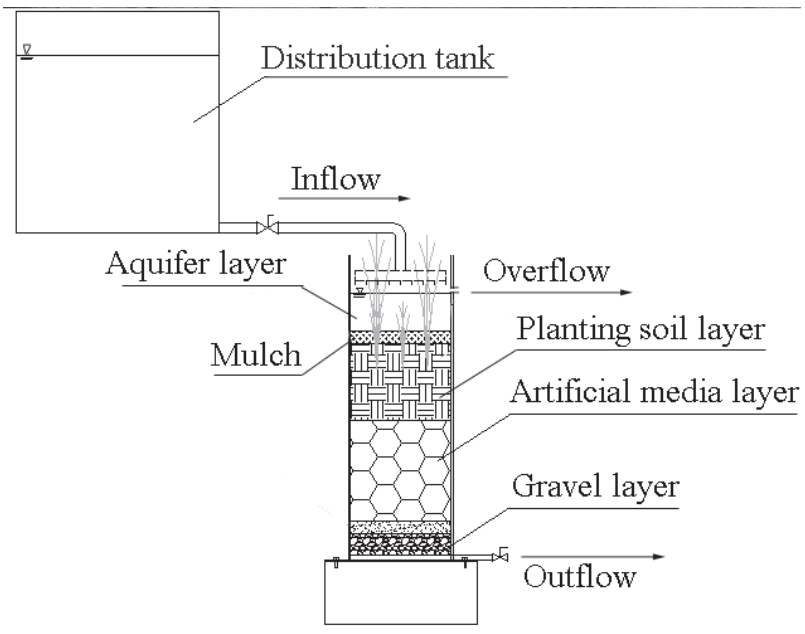

and F. Slag was set as the artificial filler in groups $\mathrm{C}$ and D to compare the hydrological performance within these groups. The plane arrangement of the experimental field and the sectional schematic of the bio-swale column are respectively shown in Figs 1, 2.

Group A (without plants) was set as the control group to find the effect of bio-swale plants on urban runoff by being compared with other vegetation groups. Group $B$ (in which five different media compositions were separately filled) was set to study the effect of artificial media composition on hydrological control. Boxwood and ryegrass (BR) were planted in Group B, border privet and Ophiopogon japonicas (BO) were planted in group E, and glossy privet and Chlorophytum comosum

Fig. 2. Sectional schematic and experimental device of bio-swale column.

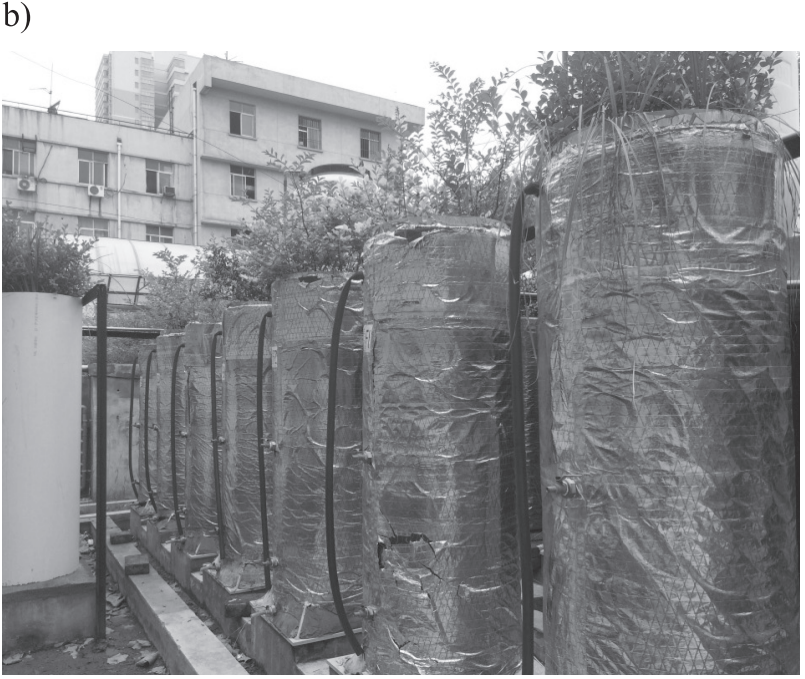


Table 1. Column experiment device design.

\begin{tabular}{|c|c|c|c|c|c|c|}
\hline Item $\quad$ Group & A & $\mathrm{B}$ & $\mathrm{C}$ & $\mathrm{D}$ & $\mathrm{E}$ & $\mathrm{F}$ \\
\hline Vegetation conditions & No & $\mathrm{BR}$ & $\mathrm{BR}$ & $\mathrm{BR}$ & $\mathrm{BO}$ & GC \\
\hline Aquifers layer & $15 \mathrm{~cm}$ & $15 \mathrm{~cm}$ & $15 \mathrm{~cm}$ & $15 \mathrm{~cm}$ & $15 \mathrm{~cm}$ & $15 \mathrm{~cm}$ \\
\hline Covering layer & $5 \mathrm{~cm}$ & $5 \mathrm{~cm}$ & $5 \mathrm{~cm}$ & $5 \mathrm{~cm}$ & $5 \mathrm{~cm}$ & $5 \mathrm{~cm}$ \\
\hline Planting soil layer thickness & $30 \mathrm{~cm}$ & $30 \mathrm{~cm}$ & $\begin{array}{c}\mathrm{C} 1, \mathrm{C} 2, \mathrm{C} 3: 30 \mathrm{~cm} \\
\mathrm{C} 4: 20 \mathrm{~cm} ; \mathrm{C} 5: 10 \mathrm{~cm}\end{array}$ & $30 \mathrm{~cm}$ & $30 \mathrm{~cm}$ & $30 \mathrm{~cm}$ \\
\hline Artificial media composition & Five types & Five types & slag & slag & Five types & Five types \\
\hline Artificial media thickness & $400 \mathrm{~mm}$ & $400 \mathrm{~mm}$ & $\begin{array}{c}\mathrm{C} 1: 30 \mathrm{~cm} ; \mathrm{C} 2, \mathrm{C} 4: 500 \mathrm{~cm} \\
\mathrm{C} 3, \mathrm{C} 5: 60 \mathrm{~cm}\end{array}$ & $400 \mathrm{~mm}$ & $400 \mathrm{~mm}$ & $400 \mathrm{~mm}$ \\
\hline Gravel layer & $15 \mathrm{~cm}$ & $15 \mathrm{~cm}$ & $15 \mathrm{~cm}$ & $15 \mathrm{~cm}$ & $15 \mathrm{~cm}$ & $15 \mathrm{~cm}$ \\
\hline Ponding depth & No & No & No & $0-500 \mathrm{~mm}$ & No & No \\
\hline $\begin{array}{l}\text { Experimental } \\
\text { purpose }\end{array}$ & $\begin{array}{l}\text { Blank } \\
\text { control }\end{array}$ & $\begin{array}{l}\text { Comparison of } \\
\text { artificial media } \\
\text { composition }\end{array}$ & $\begin{array}{l}\text { Comparison of } \\
\text { media thickness }\end{array}$ & $\begin{array}{l}\text { Comparison } \\
\text { of Ponding } \\
\text { depth }\end{array}$ & \multicolumn{2}{|c|}{$\begin{array}{l}\text { Comparison } \\
\text { of vegetation } \\
\text { conditions }\end{array}$} \\
\hline
\end{tabular}

Note: Each group from A to $\mathrm{F}$ has 5 columns. BR is boxwood and regress, BO is the combination of border privet and Ophiopogon japonicas, $\mathrm{GC}$ is the combination of glossy privet and Chlorophytum comosum 'Variegatum', Five types of artificial media composition in groups A, B, E, and F are sequentially sand, planting soil, slag, the mixture of sand and coal ash with volume ratio $5: 1$, and the mixture of sand and slag with volume ratio $1: 1$. The ponding depths of group D are sequentially $0 \mathrm{~cm}, 50 \mathrm{~cm}, 50 \mathrm{~cm}$, $40 \mathrm{~cm}$, and $30 \mathrm{~cm}$.

'Variegatum' (GC) were planted in group F. By comparing the hydrological performance of groups B, E, and F, the differences regarding the effects of vegetation conditions on retaining urban runoff can be determined. In group $\mathrm{C}$, the filler layer thicknesses were adjusted to maximize its influence on retaining moisture. Different ponding depths were set in group D to study its impact on bio-swale hydrological performance. The design of the column experiment device is presented in Table 1 .

\section{Testing Program}

To identify the main factors that affect bio-swale hydrological performance and to maximize their relationship, different setups were designed with varying inflow, vegetation conditions, media thickness, media composition, and ponding depth; the corresponding column studies were then implemented accordingly.

Running water was used in inflow distribution, and the distribution progress was controlled by manually regulating the opening degree of the drainage valve. The flux of overflow and outflow was recorded once every $6 \mathrm{~min}$. Three times parallel experiments of large, medium, and small magnitudes of runoff process were conducted for a total of nine single-factor tests, and every single-factor test covers all columns. For quantitative analysis of bioswale column hydrological performance, water reduction rate and effluent rate were chosen as the evaluation indices of water reduction. The calculated formula is:

$$
R_{V}=\frac{V_{\text {in }}-V_{\text {over }}}{V_{\text {in }}} \times 100 \%
$$

$$
R_{\text {out }}=\frac{V_{\text {out }}}{V_{\text {in }}} \times 100 \%
$$

... where $R_{v}$ is the water reduction rate, $R_{\text {out }}$ is the effluent rate, $\mathrm{V}_{\text {in }}$ is inflow $\left(\mathrm{m}^{3}\right), \mathrm{V}_{\text {out }}$ is outflow, and $\mathrm{V}_{\text {over }}$ is overflow.

\section{Influent Flow}

To highlight the effects of different inflows on reducing urban runoff volume in the bio-swale system, three different kinds of magnitude rainfall (large, medium, and small) were designed according to the rainfall intensity, where the designed return periods were 5,2 , and 0.5 years, respectively. The Chicago rainfall pattern was chosen as the design pattern. Rainfall duration was $120 \mathrm{~min}$ with a 6 min time step, and the relative position of the rainfall peak was 0.4 . The remaining parameters were determined based on the Xi'an storm intensity formula proposed by Lu [26]. The calculated rainfall amounts were 13.41, 27.92, and $37.51 \mathrm{~mm}$.

Given the bio-swale design method and the need for the column experiments to generate overflow, 8.408 $\mathrm{m}^{2}$ was selected as the corresponding confluence area of each column. Table 2 shows the calculated results of water inflow volume in the column experiment using the following formula [27]:

$$
Q=\frac{A_{d} \times H \times \varphi}{1000}
$$

...where $A_{d}$ is the corresponding confluence area, $\mathrm{m}^{2}, \mathrm{H}$ is the rainfall amount and $\varphi$ is urban road runoff coefficient, 0.9 . 
Table 2. Rainfall distribution and water inflow volume of column experiment.

\begin{tabular}{|c|c|c|c|c|c|c|}
\hline \multirow{2}{*}{$\begin{array}{l}\text { Time step/ } \\
\min \end{array}$} & \multicolumn{3}{|c|}{ Rainfall distribution } & \multicolumn{3}{|c|}{ Water inflow volume } \\
\hline & $\begin{array}{l}\text { Return period of } \\
0.5 \mathrm{a} /(\mathrm{mm} / 6 \mathrm{~min})\end{array}$ & $\begin{array}{l}\text { Return period of } \\
2 \mathrm{a} /(\mathrm{mm} / 6 \mathrm{~min})\end{array}$ & $\begin{array}{l}\text { Return period of } \\
5 \mathrm{a} /(\mathrm{mm} / 6 \mathrm{~min})\end{array}$ & $\begin{array}{l}\text { Small inflow/ } \\
\text { (L/6min) }\end{array}$ & $\begin{array}{l}\text { Medium inflow/ } \\
\text { (L/6min) }\end{array}$ & $\begin{array}{l}\text { Large inflow/ } \\
\text { (L/6min) }\end{array}$ \\
\hline 6 & 0.12 & 0.26 & 0.32 & 0.87 & 1.81 & 2.44 \\
\hline 12 & 0.13 & 0.30 & 0.37 & 1.01 & 2.09 & 2.81 \\
\hline 18 & 0.16 & 0.35 & 0.44 & 1.18 & 2.46 & 3.30 \\
\hline 24 & 0.19 & 0.42 & 0.52 & 1.42 & 2.95 & 3.96 \\
\hline 30 & 0.23 & 0.51 & 0.64 & 1.74 & 3.62 & 4.87 \\
\hline 36 & 0.29 & 0.65 & 0.82 & 2.21 & 4.61 & 6.19 \\
\hline 42 & 0.39 & 0.87 & 1.09 & 2.95 & 6.14 & 8.25 \\
\hline 48 & 0.56 & 1.24 & 1.55 & 4.20 & 8.74 & 11.74 \\
\hline 54 & 0.87 & 1.95 & 2.44 & 6.61 & 13.75 & 18.48 \\
\hline 60 & 1.63 & 3.64 & 4.57 & 12.35 & 25.71 & 34.54 \\
\hline 66 & 4.40 & 9.81 & 12.30 & 33.28 & 69.27 & 93.06 \\
\hline 72 & 1.63 & 3.64 & 4.57 & 12.35 & 25.71 & 34.54 \\
\hline 78 & 0.87 & 1.95 & 2.44 & 6.61 & 13.75 & 18.48 \\
\hline 84 & 0.56 & 1.24 & 1.55 & 4.20 & 8.74 & 11.74 \\
\hline 90 & 0.39 & 0.87 & 1.09 & 2.95 & 6.14 & 8.25 \\
\hline 96 & 0.29 & 0.65 & 0.82 & 2.21 & 4.61 & 6.19 \\
\hline 102 & 0.23 & 0.51 & 0.64 & 1.74 & 3.62 & 4.87 \\
\hline 108 & 0.19 & 0.42 & 0.52 & 1.42 & 2.95 & 3.96 \\
\hline 114 & 0.16 & 0.35 & 0.44 & 1.18 & 2.46 & 3.30 \\
\hline 120 & 0.13 & 0.30 & 0.37 & 1.01 & 2.09 & 2.81 \\
\hline Sum & 13.41 & 27.92 & 37.51 & 101.48 & 211.24 & 283.77 \\
\hline
\end{tabular}

\section{Vegetation Conditions}

Bio-swale plants play a crucial role in urban runoff reduction. Plant surfaces can retain rainwater and evaporate moisture retained in the soil through transpiration. In consideration of water resistance and environmental adaptability, three plant combinations were chosen: boxwood and ryegrass (BR, group B), border privet and Ophiopogon japonicas (BO, group E), and glossy privet and Chlorophytum comosum 'Variegatum' (GC, group F).

Given that transpiration intensity is the main factor of bio-swale plants that affects the reduction of urban runoff, it was taken as the plant factor of different vegetation conditions in the subsequent experiment analysis. To measure the transpiration intensity of selected vegetation combinations, three kinds of plant combinations (including herbs and shrubs) were separately placed in sealed sample bottles and added with equal amounts of water. After 24 hours, the measured drawdown $\left(\mathrm{H}_{1}-\mathrm{H}_{2}\right)$ was $0.10 \mathrm{~cm}$ in group $\mathrm{B}(\mathrm{BR})$, the water level dropped by $0.25 \mathrm{~cm}$ in group E (BO), and the measured drawdown $\left(\mathrm{H}_{1}-\mathrm{H}_{2}\right)$ was $0.15 \mathrm{~cm}$ in group $\mathrm{F}(\mathrm{GC})$.

\section{Media Thickness}

To study the effect of different media thickness on urban runoff reduction in bio-swale, two scenarios were designed according to the variation in media thickness. In scenario 1, the total media thickness, which consists of the planting soil layer and the artificial filler layer, is varied as a result of the artificial filler layer thickness, whereas the planting soil thickness layer and other vertical structures were kept the same. Taking columns C1, B3, C2, and C3 as examples, of which the thicknesses of the artificial filler (slag) layer were respectively $300,400,500$, and $600 \mathrm{~mm}$, the longitudinal structures of the bio-swale column above were kept the same except for the thickness of the artificial filler. In scenario 2, the artificial filler layer thickness and the planting soil thickness layer are varied at the same time, whereas the total media thickness was kept the same. Taking columns B3, C4, and C5 as examples, of which the total media thicknesses were all set to $700 \mathrm{~mm}$, the thickness of the artificial filler (slag) layer were, respectively, 400, 500, and $600 \mathrm{~mm}$, whereas the thicknesses of the planting soil were correspondingly 300,200 , and $100 \mathrm{~mm}$. 


\section{Artificial Filler Composition}

Artificial filler was added to the bio-swale to modify the condition that soil infiltration rate was poor in some areas. Combined with the actual situation of Xi'an, four different artificial fillers composition, namely, sand (No. 1), slag (No. 3), 5: 1 mixture of sand and coal ash (No. 4), and 1:1 mixture of sand and slag (No. 5), were compared with the planting soil (No. 2) so that the effects of different artificial fillers on retaining urban runoff in bio-swale can be determined. The sand was collected from the Wei River, and the soil was gathered from the planting topsoil around the school. The slag was provided by the Chang'an steel mills in Shaanxi province, China, and fly ash was composed of burned residual solids from the Baqiao power plant. The selected particles in the experiment column were screened before filling. Coarse gravel and slag were sieved in the ranges of $1.5-3 \mathrm{~cm}$ and $0.3-1.5 \mathrm{~cm}$, whereas sand was sieved at less than $0.3 \mathrm{~cm}$.

In this study, the infiltration rate was taken as the media factor of artificial filler composition in the subsequent experiment analysis. Initial experiments were conducted to measure the infiltration rate of various artificial fillers. The above-mentioned five kinds of fillers were compacted in the same waste mineral water bottle, providing the same filler thickness of $14 \mathrm{~cm}$ and a stable water head of $4 \mathrm{~cm}$;

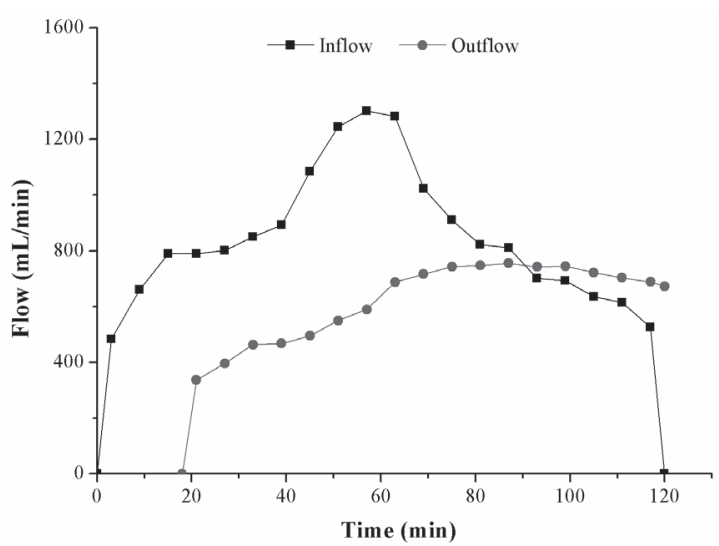

(a) Small inflow.

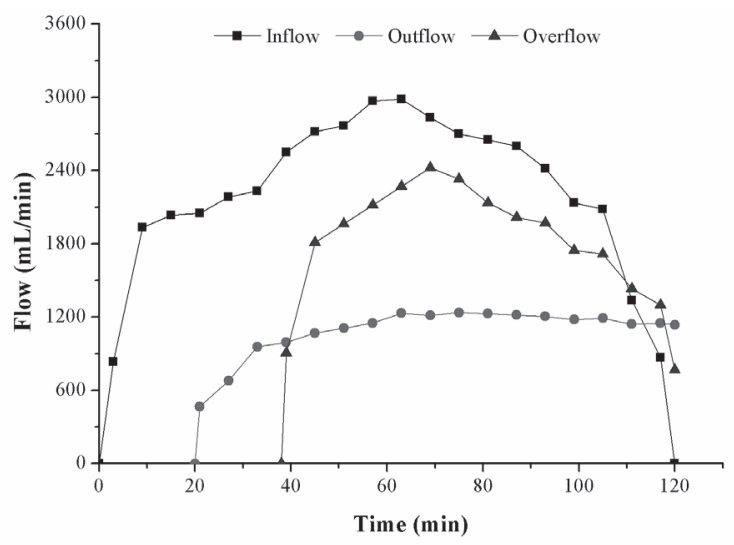

(c) Large inflow. the stable effluent time of each medium was recorded. The infiltration rate of planting soil was $0.5 \mathrm{~m} / \mathrm{d}$, as indicated by related data, and the infiltration rate of sand was converted into $1.44 \mathrm{~m} / \mathrm{d}$ based on comparisons of experiment results. The slag infiltration rate was $1.35 \mathrm{~m} / \mathrm{d}$, the infiltration rate of mixture of sand and coal ash was $0.45 \mathrm{~m} / \mathrm{d}$, and the infiltration rate of mixture of sand and slag was $1.20 \mathrm{~m} / \mathrm{d}$.

\section{Ponding Depth}

Four different ponding depths were designed to study the effects of bio-swale with different ponding depths on saving urban runoff. The ponding depths of the bio-swale column in group D were set to 0 (D1), 500 (D2), 500 (D3), 400 (D4), and $300 \mathrm{~mm}$ (D5); other vertical structures were kept the same.

\section{Results and discussion}

\section{Inflow Effects}

Taking B5 as an example, in which BR was planted and the artificial filler layer was filled with $400 \mathrm{~mm}$ mixture of sand and slag, the runoff reduction of the biological filter

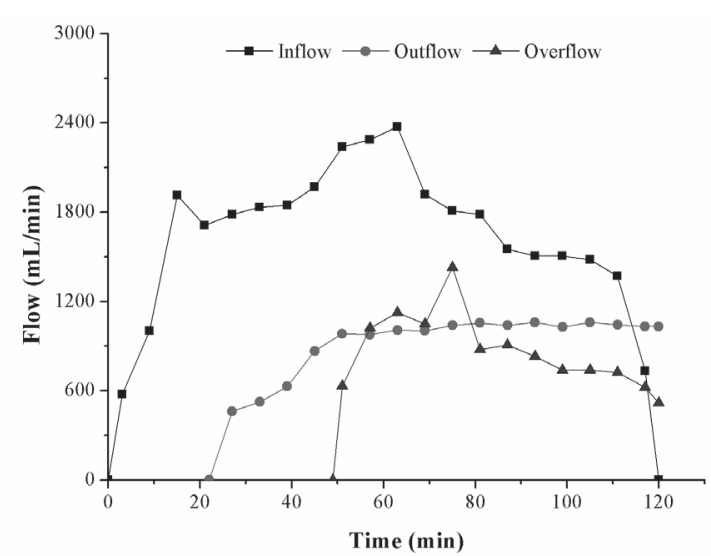

(b) Medium inflow.

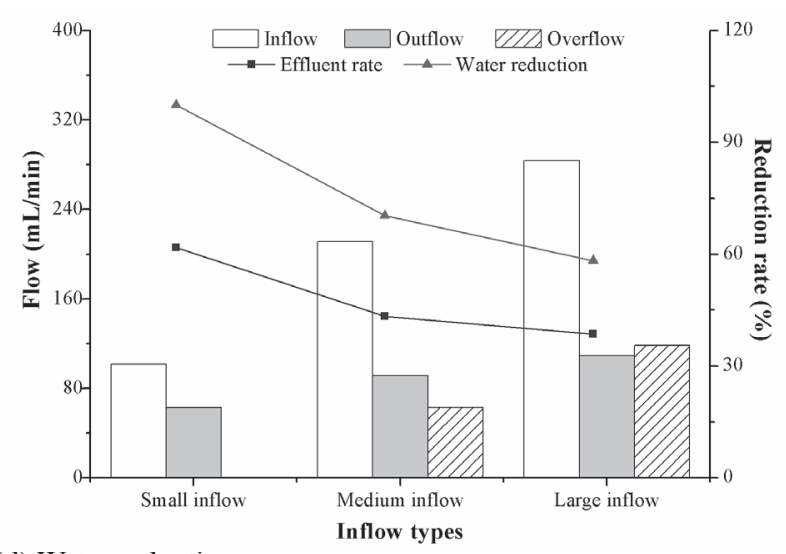

(d) Water reduction.

Fig. 3. Water flow of column B5 under different inflow conditions 
was analyzed under different influent flows. The water flow of experiment column B5 under the conditions of small, medium, and large influent flow is shown in Fig. 3.

As shown in Fig. 3, column B5 performs well both in outflow peak reduction and rainwater retention. The outflow situations of B5 were similar under different conditions of influent flow. The outflow grew quickly in the initial stages, then gradually stabilized, and eventually maintained a stable state. The reason is that the next media layer will reach saturation in the media layer only when the upper media layer becomes saturated. The bottom of the media layer gradually became saturated along with the rainfall, and the water head of the aquifer remained at a stable level at the same time. Thus, the outflow in the later period was more stable.

Under the conditions of medium and large influent flows, B5 began to overflow, but no overflow occurred at small inflow. The waveform diagram of overflow was similar to that of influent flow. During the rainfall, the aquifer water level increased as the inflow amount increased. Once the aquifer layer reaches saturation, overflow will occur. The overflow will increase with the inflow until maximum inflow occurs. Then the overflow was gradually reduced with the decrease in inflow. Meanwhile, the infiltration, rather than the inflow, gradually took over the dominant position. At the end of the rainfall, the overflow stopped when the influent flow was close to zero.

Under three different inflow conditions (low, medium, and large), the effluent rates of B5 were, respectively, $61.82 \%, 41.83 \%$, and $38.53 \%$, whereas the water reduction rates were $100 \%, 70.31 \%$, and $58.27 \%$ (Fig. 3-d); the significant difference was shown by t-distribution tests. Water reduction rate decreases as inflow increases. The reason is that retaining rainwater in the bio-swale system mainly relies on the infiltration rate of the planting soil and filler. When inflow increases, bio-swale infiltration ability will not vary with influent flow. In conclusion, the maximum water flow storage and stagnation capacity of a bio-swales system were limited, and when the influent flow exceeded the capacity, overflow would occur and thus lose the ability to continue retaining rainwater. Therefore,

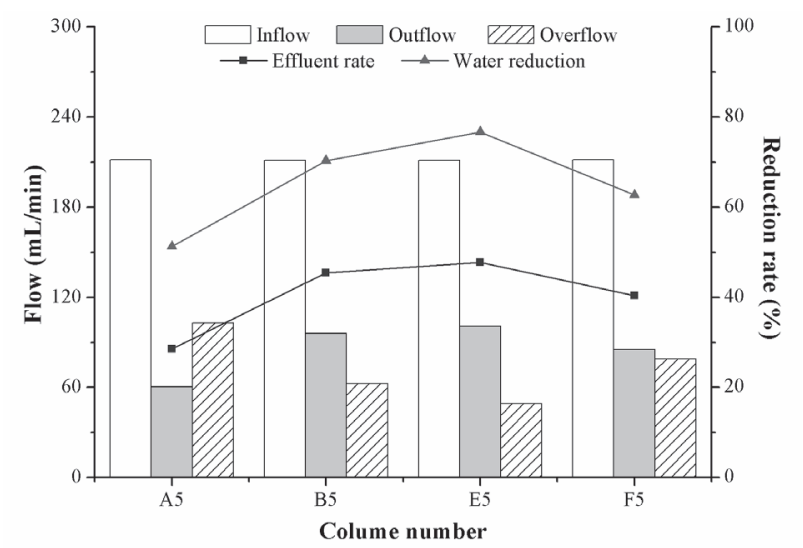

Fig. 4. Water reduction of different plants in conditions of medium water flow. overflow will gradually increase with the increase in influent water.

\section{Vegetation Condition Effects}

Taking columns B5, E5, and F5 as examples, in which vegetation was respectively $\mathrm{BR}, \mathrm{BO}$, and $\mathrm{GC}$, their water reductions were analyzed by comparing them with that of column A5 without plants under the condition of medium influent flow (Fig. 4). The vertical structures of the experiment column above are consistent, except for the vegetation condition.

Given that the vertical structures of columns A5, B5, E5, and F5 were consistent, the order of the water reduction rate in the bio-swale column above with different vegetation conditions was as follows: E5 $(76.67 \%)>$ B5 $(70.31 \%)>$ F5 $(62.67 \%)>$ A5 (52.28\%), and a significant difference was shown using t-distribution test. Fig. 4 shows that the effect of different vegetation conditions on water reduction was characterized by the following order: $\mathrm{BO}>\mathrm{BR}>\mathrm{GC}>$ no plant; this order is consistent with the results of a previous plant factor test. The transpiration intensity of BO was larger, followed by the combination of $\mathrm{BR}$, whereas the transpiration of GC was relatively weak. This probably depends on the transpiration of the plant combination. In bio-swales systems, the effects of plants on retaining water were not exerted by directly affecting the stagnation ability during operation. Plants absorbed moisture in the soil by transpiration during drought periods, thereby reducing the soil moisture content and playing an indirect role in increasing the retain capacity. Therefore, the stronger transpiration ability that plants have, the better water reduction the bio-swales would perform.

\section{Media Thickness Effects}

1) Different total media thickness (scenario 1)

Under the condition of medium influent flow, the hydrological performance of columns C1, B3, C2, and $\mathrm{C} 3$, which had different thicknesses of the artificial filler

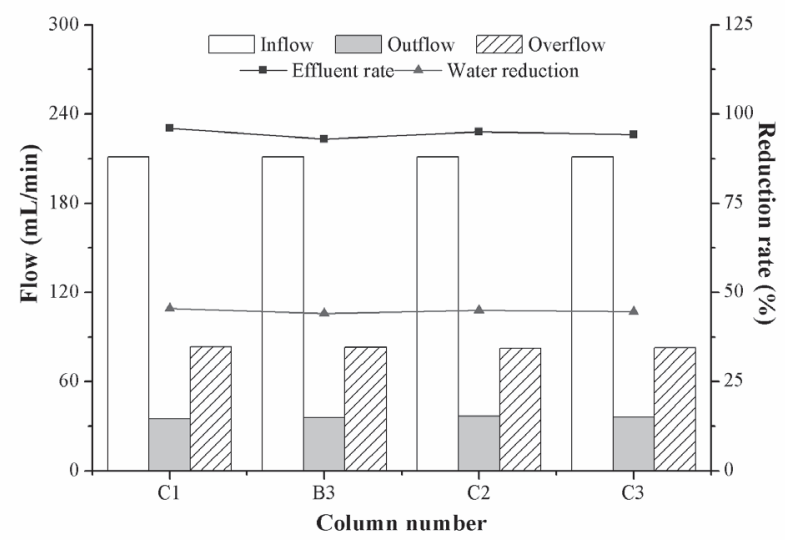

Fig. 5. Water reduction of different media thickness in conditions of medium inflow (scenario 1). 


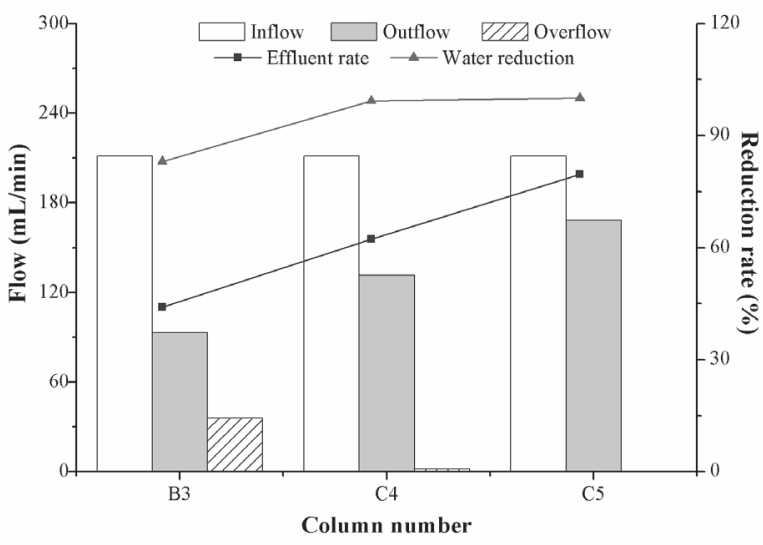

Fig. 6. Water reduction of different media thickness in conditions of medium inflow (scenario 2).

(scenario 1), was comprehensively compared (Fig. 5). The longitudinal structures of the bio-swale column above were set to be the same except for the thickness of artificial filler.

Fig. 5 shows that the control effects of columns $\mathrm{C} 1$, B3, C2, and C3 were substantially close, such that other vertical structures were consistent under the same inflow conditions. Water reduction rate was almost the same at $83.52 \%, 83.09 \%, 82.67 \%$, and $82.95 \%$, and only slight differences were shown by the t-distribution test. Overall, under the preconditions that planting soil layer thickness were certain, the thickness of the artificial filler layer showed a slight effect on urban runoff reduction in bioswale.

2) Different planting soil thickness (scenario 2)

Under the conditions of medium influent flow, the water reduction of bio-swale columns B3, C4, and C5, which had different planting soil layer thicknesses and the same total media thickness, was comprehensively compared.

Fig. 6 shows that water reduction rate and the effluent rate increased as the thickness of the planting soil

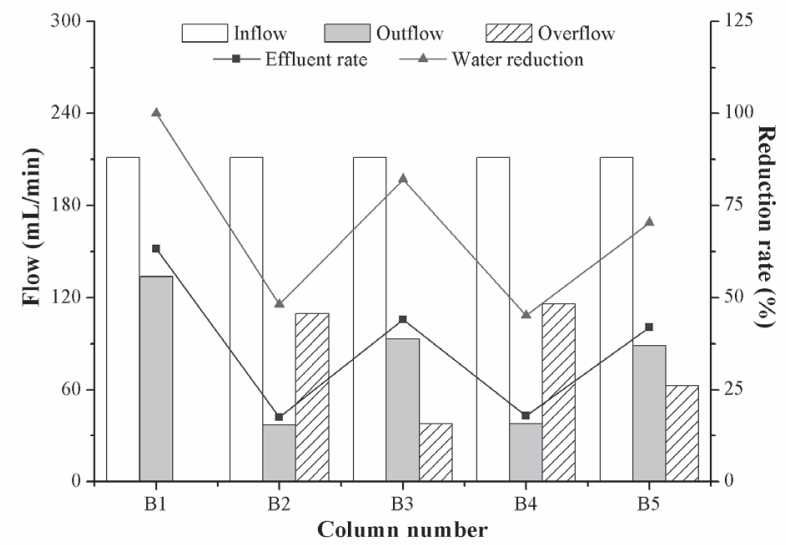

Fig. 7. Water reduction of different artificial media composition in conditions of medium inflow. decreased, and a significant difference was shown by the t-distribution test. This was on the account that planting soil infiltration rate was almost the lowest (slightly higher than that of the filler mixed with fly ash) as compared to the average infiltration rate of the artificial filler layer or the fine gravel layer. Therefore, the planting soil thicknesses would directly affect the infiltration in the entire bio-swales system. When the bio-swales system reaches saturated infiltration, overflow will occur, and water reduction will decrease as soil thickness increases. In bio-swales systems, soil thickness is one of the most important factors affecting water reduction.

\section{Artificial Media Composition Effects}

Under the conditions of medium influent flow, the reduction of $\mathrm{B} 1, \mathrm{~B} 2, \mathrm{~B} 3, \mathrm{~B} 4$, and $\mathrm{B} 5$, which were filled with different artificial media compositions, was comprehensively compared.

The order of water reduction rate in bio-swale column above was B1 $(100 \%)>$ B3 $(82.09 \%)>$ B $5(70.31 \%)>$ B2 $(48.12 \%)>$ B4 $(45.12 \%)$, and significant difference was shown by the t-distribution test (Fig. 7). The order of the effect on the reduction rate with different artificial media compositions was sand $>$ slag $>$ mixture of sand and slag $>$ planting soil $>$ mixture of coal ash and sand. This order is consistent with the order of artificial filler infiltration rate. The reason is that different artificial media compositions performed at different infiltration rates. Only when the upper media layer becomes saturated will the next media layer reach saturation in the media layer. Owing to the large difference among the average infiltration rates of fillers, bio-swales would show a greater diversification in water reduction. Under the condition that the infiltration rate of the artificial filler was exponentially greater than that of planting soil, bio-swales would show high water reduction, and overflow would occur until the soil layer became saturated. In case the infiltration rate of the artificial filler was close to or even below the soil infiltration rate, the overflow was supposed to consider media thickness.

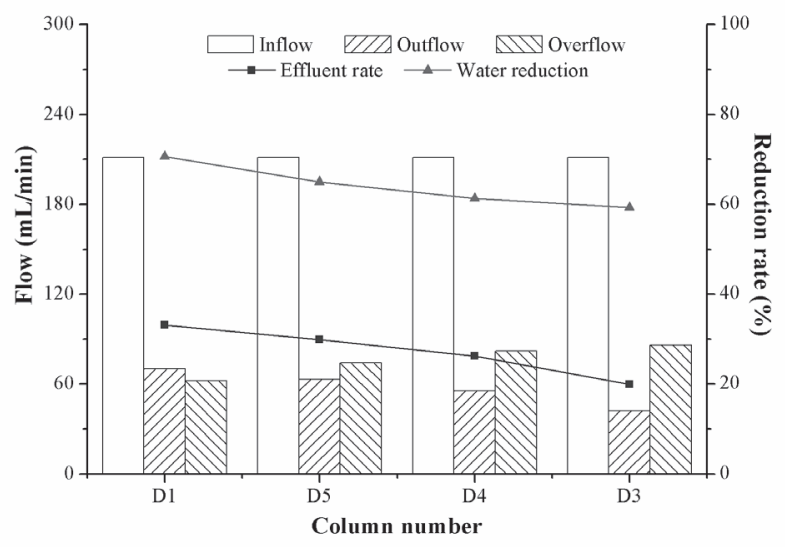

Fig. 8. Water reduction of different ponding depths at medium inflow in bio-swale column group D. 
Therefore, the water reductions will increase with the increase in media infiltration rate.

As a result, the bio-swale column with high-infiltration rate artificial filler produced better hydrological control effect, and sand was proven to be the optimal media among the selected media compositions.

\section{Ponding Depth Effects}

Taking columns D1, D3, D4, and D5 as examples, which had different ponding depths, the longitudinal structures of the bio-swale columns above were set to be the same. The water reduction of experiment columns D1, D3, D4, and D5 under medium inflow conditions is shown in Fig. 8.

Fig. 8 shows that under the conditions of medium influent flow, the order of water reduction rate in columns D1, D3, D4, and D5, which had different ponding depths, was D1 $(70.61 \%)>$ D5 $(64.97 \%)>$ D4 $(61.26 \%)>$ D3 $(59.25 \%)$, and significant difference was shown by the t-distribution test. Results showed that the reduction rate decreased as the ponding depth increased. The reason is that setting anaerobic ponding depth at the bottom performed some impact on retaining inflow in the bioswale system. Cleaned rain water, which should infiltrate or discharge through the perforated collection tube, could not be discharged in a timely manner. As a result, the infiltration rates of layer and gravel layer would change, thereby affecting the soil saturation state and making it advanced. Thus, with the increase in ponding depth, water reduction will gradually decrease.
Simulation with Stepwise Regression Model

\section{Curve Analysis}

Bio-swales were proven to produce various water reductions under different conditions such as inflow, vegetation, media composition, soil thickness, and ponding depth. Previous column studies have posited that bio-swales would show better water reduction when planted with strong transpiration intensity vegetation and filled with high-permeability artificial fillers with lower planting soil thickness and without ponding depth at the bottom under smaller inflow. To obtain the relationship between water reduction and its influencing factors, the corresponding correlation analysis should be implemented. Using SPSS software, linear analysis was conducted on the relationship between water reduction rate and influence factors, such as the influent flow, vegetation condition, planting soil thickness, artificial filler compositions, and ponding depth.

To find the relationship between the inflow and water reduction, and ensure that the relationship curve analysis was more accurate, multi-group column analyses were implemented. Results show that water reduction rate and influent flow had a strong linear and decreasing relationship (Table 3).

During correlation analysis, the selected columns should consider excluding the effect of other factors on vegetation conditions. Thus, the water reduction in groups $\mathrm{A}, \mathrm{B}, \mathrm{E}$, and $\mathrm{F}$ were taken to estimate the relationship;

Table 3. Estimation of inflow and water reduction.

\begin{tabular}{|c|c|c|c|}
\hline Column Number & Curve Analysis & Column Number & Curve Analysis \\
\hline A1 & $\mathrm{y}=-0.190 \mathrm{x}+120.292\left(\mathrm{R}^{2}=0.985\right)$ & $\mathrm{D} 1$ & $\mathrm{y}=-0.082 \mathrm{x}+87.829\left(\mathrm{R}^{2}=1\right)$ \\
\hline A2 & $\mathrm{y}=-0.130 \mathrm{x}+71.183\left(\mathrm{R}^{2}=0.847\right)$ & $\mathrm{D} 2$ & $\mathrm{y}=-0.106 \mathrm{x}+81.588\left(\mathrm{R}^{2}=0.937\right)$ \\
\hline A3 & $\mathrm{y}=-0.342 \mathrm{x}+133.738\left(\mathrm{R}^{2}=0.996\right)$ & $\mathrm{D} 3$ & $\mathrm{y}=-0.164 \mathrm{x}+84.644\left(\mathrm{R}^{2}=0.776\right)$ \\
\hline A4 & $\mathrm{y}=-0.106 \mathrm{x}+62.597\left(\mathrm{R}^{2}=0.761\right)$ & $\mathrm{D} 4$ & $\mathrm{y}=-0.068 \mathrm{x}+74.994\left(\mathrm{R}^{2}=0.952\right)$ \\
\hline A5 & $\mathrm{y}=-0.202 \mathrm{x}+107.083\left(\mathrm{R}^{2}=0.728\right)$ & $\mathrm{D} 5$ & $\mathrm{y}=-0.059 \mathrm{x}+76.408\left(\mathrm{R}^{2}=0.977\right)$ \\
\hline B1 & $\mathrm{y}=-0.072 \mathrm{x}+109.505\left(\mathrm{R}^{2}=0.643\right)$ & $\mathrm{E} 1$ & $\mathrm{y}=-0.076 \mathrm{x}+109.848\left(\mathrm{R}^{2}=0.678\right)$ \\
\hline B2 & $\mathrm{y}=-0.211 \mathrm{x}+88.436\left(\mathrm{R}^{2}=0.963\right)$ & $\mathrm{E} 2$ & $\mathrm{y}=-0.169 \mathrm{x}+90.452\left(\mathrm{R}^{2}=0.840\right)$ \\
\hline B3 & $\mathrm{y}=-0.172 \mathrm{x}+118.027\left(\mathrm{R}^{2}=0.994\right)$ & $\mathrm{y}=-0.167 \mathrm{x}+112.498\left(\mathrm{R}^{2}=0.905\right)$ \\
\hline B4 & $\mathrm{y}=-0.183 \mathrm{x}+75.186\left(\mathrm{R}^{2}=0.831\right)$ & $\mathrm{y}=-0.317 \mathrm{x}+126.425\left(\mathrm{R}^{2}=0.993\right)$ \\
\hline B5 & $\mathrm{y}=-0.232 \mathrm{x}+122.393\left(\mathrm{R}^{2}=0.985\right)$ & $\mathrm{y}=-0.201 \mathrm{x}+120.022\left(\mathrm{R}^{2}=0.998\right)$ \\
\hline C1 & $\mathrm{y}=-0.117 \mathrm{x}+118.062\left(\mathrm{R}^{2}=0.991\right)$ & $\mathrm{F} 1$ & $\mathrm{y}=-0.067 \mathrm{x}+108.688\left(\mathrm{R}^{2}=0.690\right)$ \\
\hline C2 & $\mathrm{y}=-0.168 \mathrm{x}+117.349\left(\mathrm{R}^{2}=0.998\right)$ & $\mathrm{F}=-0.017 \mathrm{x}+56.364\left(\mathrm{R}^{2}=0.190\right)$ \\
\hline C3 & $\mathrm{y}=-0.174 \mathrm{x}+118.259\left(\mathrm{R}^{2}=0.993\right)$ & $\mathrm{F} 4$ & $\mathrm{y}=-0.190 \mathrm{x}+111.999\left(\mathrm{R}^{2}=0.881\right)$ \\
\hline C4 & $\mathrm{y}=-0.068 \mathrm{x}+118.965\left(\mathrm{R}^{2}=0.636\right)$ & $\mathrm{y}=-0.066 \mathrm{x}+66.855\left(\mathrm{R}^{2}=0.413\right)$ \\
\hline C5 & $-\mathrm{x}$ & $\mathrm{y}=-0.232 \mathrm{x}+120.093\left(\mathrm{R}^{2}=0.893\right)$ \\
\hline
\end{tabular}

Note: $\mathrm{y}$ is water reduction, $\mathrm{x}$ is inflow and $\mathrm{R}^{2}$ is the correlation coefficient. 
Table 4. Estimation of vegetation conditions and water reduction.

\begin{tabular}{|c|c|c|c|}
\hline Number & Low inflow & Medium inflow & Large inflow \\
\hline & - & $\mathrm{y}=64.108 \mathrm{x}+87.257\left(\mathrm{R}^{2}=0.616\right)$ & $\mathrm{y}=78.954 \mathrm{x}+70.751\left(\mathrm{R}^{2}=0.604\right)$ \\
\hline $1 \#$ & - & $\mathrm{y}=35.325 \mathrm{x}+41.125\left(\mathrm{R}^{2}=0.509\right)$ & $\mathrm{y}=56.738 \mathrm{x}+34.178\left(\mathrm{R}^{2}=0.245\right)$ \\
\hline $2 \#$ & $\mathrm{y}=55.362 \mathrm{x}+57.327\left(\mathrm{R}^{2}=0.437\right)$ & - & $\mathrm{y}=123.008 \mathrm{x}+43.372\left(\mathrm{R}^{2}=0.658\right)$ \\
\hline $3 \#$ & $\mathrm{y}=32.138 \mathrm{x}+53.848\left(\mathrm{R}^{2}=0.453\right)$ & $\mathrm{y}=101.423 \mathrm{x}+33.315\left(\mathrm{R}^{2}=0.955\right)$ & - \\
\hline $4 \#$ & $\mathrm{y}=31.808 \mathrm{x}+93.957\left(\mathrm{R}^{2}=0.641\right)$ & $\mathrm{y}=103.531 \mathrm{x}+52.291\left(\mathrm{R}^{2}=0.974\right)$ & $\mathrm{y}=24.577 \mathrm{x}+56.690\left(\mathrm{R}^{2}=0.880\right)$ \\
\hline $5 \#$ & & &
\end{tabular}

Note: $\mathrm{y}$ is water reduction, $\mathrm{x}$ is plant factor and $\mathrm{R}^{2}$ is the correlation coefficient.

the main medium composition was set the same except that different kinds of vegetation were planted. As a result, a strong linear and increasing relationship was shown between the plant factor and water reduction rate (Table. 4).

As there was a high infiltration rate artificial filler layer under the soil layer, the reduction of whole bio-swales maintained a high level. Bio-swale columns B3, C4, and $\mathrm{C} 5$, which had different soil thicknesses under large inflow, were comprehensively compared to implement curve analysis. The calculated curve between different planting soil thicknesses $(\mathrm{x})$ and water reduction $(\mathrm{y})$ was $y=-1.582 x+116.613, \mathrm{R}^{2}=0.993$. As a result, a relatively strong linear and decreasing relationship was shown between the water reduction rate and planting soil thickness.

Taking the bio-swale groups A, B, E, and F as examples, which were filled with different artificial media compositions under the condition of different inflows, curve analysis was performed between media factor and water reduction. Results show that there was a strong linear and increasing relationship between water reduction rate and media factor (Table 5).

Group D was designed for studying the relationship between ponding depth and water reduction. Columns D1, D3, D4, and D5, which were set with different ponding depths, were chosen to implement curve analysis under the condition of different inflows. Results show that the water reduction rate decreased linearly as ponding depth increased (Table 5).

\section{Linear Fitting}

According to the curve analysis, above, a linear relationship existed between the water reduction rate and its influencing factors, such as influent flow, plant factor, planting soil thickness, infiltration rate of artificial filler, and ponding depth. The stepwise regression method in the SPSS software was utilized to establish the model. As a result, the multiple linear regression model was obtained as follows:

$$
\begin{gathered}
Y=80.515-0.130 X_{1}+46.301 X_{2}+38.955 X_{3} \\
-0.566 X_{4}-1.011 X_{5}
\end{gathered}
$$

... where $Y$ is the water reduction rate, $X_{1}$ is the influent flow, $X_{2}$ was plant factor, $X_{3}$ is the infiltration rate of artificial filler, $X_{4}$ is ponding depth, and $X_{5}$ is planting soil thickness.

Deterministic coefficient (Nash-suttcliffe simulation efficiency coefficient) [28] was chosen to verify the simulation results. Nash-suttcliffe simulation efficiency coefficient (Ens) was calculated as follows:

Table 5. Estimation of media composition, ponding depth, and water reduction.

\begin{tabular}{|c|c|c|c|}
\hline \multirow{2}{*}{$\begin{array}{c}\text { Group } \\
\text { Number }\end{array}$} & Low inflow & Medium inflow & Large inflow \\
\cline { 2 - 4 } & $\mathrm{y}=45.720 \mathrm{x}+35.723\left(\mathrm{R}^{2}=0.994\right)$ & $\mathrm{y}=37.967 \mathrm{x}+16.407\left(\mathrm{R}^{2}=0.831\right)$ & $\mathrm{y}=17.920 \mathrm{x}+28.683\left(\mathrm{R}^{2}=0.385\right)$ \\
\hline $\mathrm{A}$ & $\mathrm{y}=47.049 \mathrm{x}+36.972\left(\mathrm{R}^{2}=0.950\right)$ & $\mathrm{y}=46.732 \mathrm{x}+23.157\left(\mathrm{R}^{2}=0.915\right)$ & $\mathrm{y}=58.860 \mathrm{x}-6.832\left(\mathrm{R}^{2}=0.961\right)$ \\
\hline $\mathrm{B}$ & $\mathrm{y}=35.167 \mathrm{x}+52.207\left(\mathrm{R}^{2}=0.889\right)$ & $\mathrm{y}=34.958 \mathrm{x}+36.408\left(\mathrm{R}^{2}=0.724\right)$ & $\mathrm{y}=38.628 \mathrm{x}+21.680\left(\mathrm{R}^{2}=0.892\right)$ \\
\hline $\mathrm{E}$ & $\mathrm{y}=43.549 \mathrm{x}+40.017\left(\mathrm{R}^{2}=0.933\right)$ & $\mathrm{y}=36.879 \mathrm{x}+27.585\left(\mathrm{R}^{2}=0.672\right)$ & $\mathrm{y}=21.681 \mathrm{x}+41.799\left(\mathrm{R}^{2}=0.564\right)$ \\
\hline $\mathrm{F}$ & $\mathrm{y}=-0.309 \mathrm{x}+79.349\left(\mathrm{R}^{2}=0.996\right)$ & $\mathrm{y}=-0.229 \mathrm{x}+70.895\left(\mathrm{R}^{2}=0.983\right)$ & $\mathrm{y}=-0.839 \mathrm{x}+74.273\left(\mathrm{R}^{2}=0.999\right)$ \\
\hline $\mathrm{D}$ & $\mathrm{y}$
\end{tabular}

Note: $\mathrm{y}$ is water reduction and $\mathrm{R}^{2}$ is the correlation coefficient; $\mathrm{x}$ is media factor in groups $\mathrm{A}, \mathrm{B}, \mathrm{E}$ and $\mathrm{F}$, while, $\mathrm{x}$ is ponding depth in group D. 


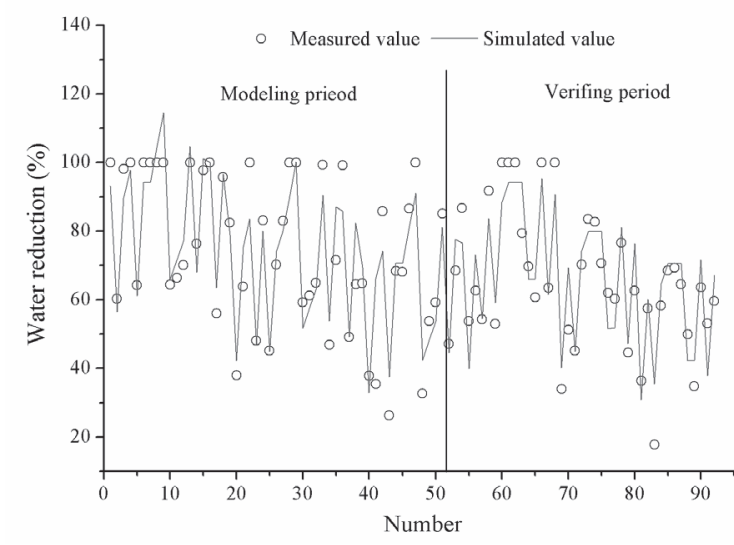

Fig. 9-a. Comparison of simulated and measured values.

$$
E n s=1-\frac{\sum_{i=1}^{n}\left(Q_{0}-Q_{p}\right)^{2}}{\sum^{n}\left(Q_{0}-Q_{\text {avg }}\right)^{2}}
$$

...where $\mathrm{Q}_{0}$ is the measured value, $\mathrm{Q}_{\mathrm{p}}$ is the simulated value, $Q_{a v g}$ is the average value of measured data, and $n$ is the total number of measured data.

The calculated results were obtained as follows: Ens of simulation was 0.8582 ; and Ens of verifying was 0.8324 . The comparison of simulated and measured values of water reduction rate in the stepwise regression model and the residual analysis of water reduction was shown in Fig. 9.

As shown in Fig. 9-a, the differences were small between the simulated and measured values in the model. Combined with the deterministic coefficient, the Ens values of the simulated and tested were relatively close to 0.85 , indicating that the simulated equation was an appropriate and reasonable choice.

Fig. 9-b shows that the residual values fluctuate generally between \pm 10 , and the values were comparatively concentrated near zero, indicating that the simulated value was close to the measured values. Error analysis was carried out by tracking the points with larger residuals:

1) The simulated values of $D$ group were substantially higher than that of the measured value. This phenomenon was primarily due to the shredded newspaper in group D (preparation for the related water quality test). The shredded newspaper embedded in advance may affect the normal infiltration and indirectly change the original permeability of media composition. As a result, permeability decreased, thereby altering water reduction.

2) Some residuals were found in the small inflow experiment. This was on account that the small magnitude runoff process was carried out at the initial period of the experiment, and the stability of the system might have difficulty in meeting the requirements at the initial operation process. Therefore, some residual errors were caused by system errors.

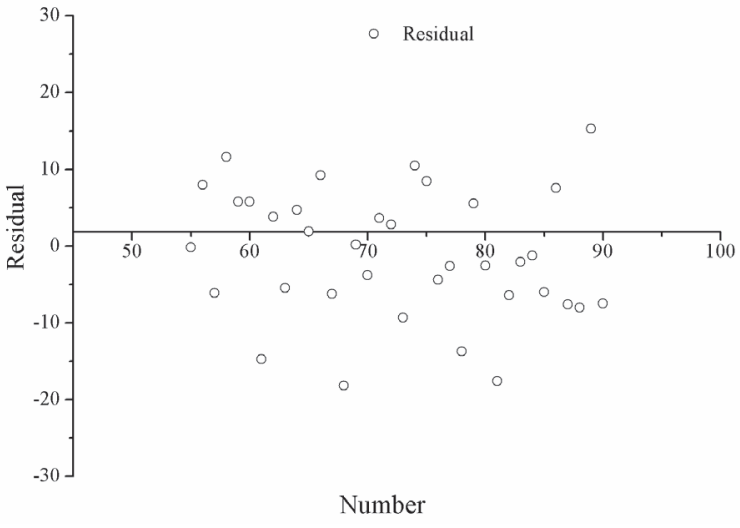

Fig. 9-b. Residual of water flow reduction.

\section{Conclusions}

Water reduction in the bio-swale will increase as inflow increases; the order of vegetation improving bioswale water reduction tends to be same with the order of its plant factor: border privet and Ophiopogon japonicus $>$ boxwood and ryegrass $>$ glossy privet and Chlorophytum comosum 'Variegatum' $>$ no plant. The water reduction rate in the bio-swale column increases dramatically with the decrease of planting soil thickness, and no significant change occurs once the thickness of the artificial filler layer alters. The order of water reduction improvement among experiment column, which was filled with different artificial filler, was: sand $>$ slag $>$ mixture of sand and slag $>$ planting soil $>$ mixture of coal ash and sand factor, and it showed the same tendency with its infiltration rate. Water reduction rate decreases with the increase in the ponding depth. Column studies have posited that bio-swales would show better water reduction, which was planted vegetations with strong transpiration intensity, filled with high permeability artificial fillers with lower planting soil thickness and without ponding depth at the bottom under smaller inflow.

Curve analysis was conducted on the relationship between water reductions rate and influencing factors, such as the influent flow, vegetation conditions, planting soil thickness, artificial filler combinations, and ponding depth. The results show that a linear relationship existed between the various factors mentioned above and the water reduction rate of the bio-swale column. Water reduction rate is linearly reduced as influent flow, soil thickness, and ponding depth increase. Vegetation conditions and the infiltration rate of artificial filler grow linearly with the increase in water reduction rate. In addition, using SPSS software based on stepwise regression model, the statistical relationship between factors and water quantity reductions was analyzed, combined with the experiment results. 


\section{Acknowledgements}

This research was financially supported by the National Natural Science Foundation of China (Nos. 51279158 and 51209168) and the Natural Science Foundation of Shaanxi Province (No. 2015JZ013).

\section{References}

1. NOVOTNY V. Nonpoint pollution and urban stormwater management. Technomic, Lancaster, PA, 1995.

2. USEPA. Low impact development (LID): A literature review. EPA-841-B-00-005, Office of Water, Washington, DC, 2000.

3. COFFMAN L. Low-impact development design strategies, an integrated design approach. EPA 841-B-00-003, Dept. of Environmental Resources, Programs, and Planning Division, Prince George's County, MD, 2000.

4. CHANG N.B. Hydrological connections between low-impact development, watershed best management practices, and sustainable development. J. Hydrol. Eng. 15, 384, 2010.

5. DAVIS A.P., SHOKOUHIAN M., SHARMA H., MINAMI C. Laboratory study of biological retention for urban stormwater management. Water Environ. Res. 73, 5, 2001.

6. SEBY F., POTIN-GAUTIER M., GIFFAUT E., BORGE G., DONARD O.F. X. A critical review of thermodynamic data for selenium species at $25^{\circ} \mathrm{C}$. Chem. Geol. 171, 173, 2001.

7. TROWSDALE S.A., SIMCOCK R. Urban stormwater treatment using bioretention. J. Hydrol. 397 (3-4), 167, 2011.

8. LIU J., DAVIS A. P. Phosphorus Speciation and Treatment Using Enhanced Phosphorus Removal Bioretention. Environ. Sci. Technol. 48, 607, 2014.

9. HUNT W.F., JARRETT A.R., SMITH J. T., SHARKEY L.J. Evaluating bioretention hydrology and nutrient removal at three field sites in North Carolina. J. Irrg. Drain. Eng. 132, 600, 2006.

10. HEASOM W., TRAVER R., WELKER A. Hydrologic modeling of a bioinfiltration best management practice. J. Am. Water Resour. As. 42, 1329, 2006.

11. HUNT W. F., SMITH J. T., JADLOCKI S. J., HATHAWAY J. M., EUBANLS P. R. Pollutant removal and peak flow mitigation by a bioretention cell in urban Charlotte, NC. J. Environ. Eng. 134, 403, 2008.

12. DAVIS A.P. Field performance of bioretention: Hydrology impacts. J. Hydrol. Eng. 13, 90, 2008.

13. LI H., SHARKEY L. J., HUNT W. F., DAVIS A. P. Mitigation of impervious surface hydrology using bioretention in Maryland and North Carolina. J. Hydrol. Eng. 14, 407, 2009.

14. DAVIS A.P., TRAVER R.G., HUNT W.F., BROWN R.A., LEE R., OLSZEWSKI J. M. Hydrologic performance of bioretention stormwater control measures. J. Hydrol. Eng. 17, 604, 2012.

15. HUNT W.F., DAVIS A.P., TRAVER R.G. Meeting Hydrologic and Water Quality Goals through Targeted Bioretention Design. J. Environ. Eng. 138, 698, 2012.

16. OLSZEWSKI J.M., DAVIS A.P. Comparing the Hydrologic Performance of a Bioretention Cell with Predevelopment Values. J. Irrg. Drain. Eng. 139, 124, 2013.

17. BARRETT M.E., LIMOUZIN M., LAWLER D.F. Effects of media and plant selection on biofiltration performance. J. Environ. Eng. 139, 462, 2013

18. O'NEILL S.W., DAVIS A.P. Water treatment residual as a bioretention amendment for phosphorus. I: Evaluation studies. J. Environ. Eng. 138, 318, 2012.

19. O'NEILL S.W., DAVIS A.P. Water treatment residual as a bioretention amendment for phosphorus. II: Long-term column studies. J. Environ. Eng. 138, 328, 2012.

20. GLAISTER B.J., FLETCHER T.D., COOK P.L., HATT B.E. Co-optimisation of phosphorus and nitrogen removal in stormwater biofilters: the role of filter media, vegetation and saturated zone. Water Sci. Technol. 69, 1961, 2014.

21. PAUS K.H., MORGAN J., GULLIVER J.S., HOZALSKI R.M. Effects of bioretention media compost volume fraction on toxic metals removal, hydraulic conductivity, and phosphorous release. J. Environ. Eng. 140, 04014033-1, 2014.

22. PAUS K.H., MORGAN J., GULLIVER J.S., LEIKNES T., HOZALSKI R.M. Effects of temperature and $\mathrm{NaCl}$ on toxic metal retention in bioretention media. J. Environ. Eng. 140, 04014034-1, 2014.

23. FENG W., HATT B.E., MCCARTHY D.T., FLETCHER T.D., DELETIC A. Biofilters for stormwater harvesting: understanding the treatment performance of key metals that pose a risk for water use. Environ. Sci. technol. 46, 5100, 2012.

24. LIM H.S., LIM W., HU J.Y., ZIEGLER A., ONG S.L. Comparison of filter media materials for heavy metal removal from urban stormwater runoff using biofiltration systems. J. Environ. Manage. 147, 24, 2015.

25. GUO H., LIM F.Y., ZHANG Y., LEE L.Y., HU J.Y., ONG S.L.,YAU W.L., ONG G.S. Soil column studies on the performance evaluation of engineered soil mixes for bioretention systems. Desalin. Water Treat. 54, 3661, 2015.

26. LU J.S., CHEN Y., ZHENG Q., RUI D.U., WANG S.P., WANG J.P. Derivation of Rainstorm Intensity Formula in Xi'an City. China water \& waste water. 26 (17), 82, 2010 [in Chinese].

27. KUICHLING E. The relation between the rainfall and the discharge of sewers in populous districts. T. Am. Soc. Civil Eng. 20, 11,1889.

28. NASH J. E., SUTCLIFFE J. V. River flow forecasting through conceptual models, Part I: A discussion of principles. J. Hydrol. 10 , 282, 1970. 